\title{
Analysis of Water Hammer with Different Closing Valve Laws on Transient Flow of Hydrogen-Natural Gas Mixture
}

\author{
Norazlina Subani and Norsarahaida Amin \\ Department of Mathematical Sciences, Faculty of Science, Universiti Teknologi Malaysia (UTM), 81310 Johor Bahru, Johor, Malaysia \\ Correspondence should be addressed to Norsarahaida Amin; norsarahaida@utm.my
}

Received 14 March 2015; Accepted 10 April 2015

Academic Editor: Marco Donatelli

Copyright ( $) 2015$ N. Subani and N. Amin. This is an open access article distributed under the Creative Commons Attribution License, which permits unrestricted use, distribution, and reproduction in any medium, provided the original work is properly cited.

\begin{abstract}
Water hammer on transient flow of hydrogen-natural gas mixture in a horizontal pipeline is analysed to determine the relationship between pressure waves and different modes of closing and opening of valves. Four types of laws applicable to closing valve, namely, instantaneous, linear, concave, and convex laws, are considered. These closure laws describe the speed variation of the hydrogennatural gas mixture as the valve is closing. The numerical solution is obtained using the reduced order modelling technique. The results show that changes in the pressure wave profile and amplitude depend on the type of closing laws, valve closure times, and the number of polygonal segments in the closing function. The pressure wave profile varies from square to triangular and trapezoidal shape depending on the type of closing laws, while the amplitude of pressure waves reduces as the closing time is reduced and the numbers of polygonal segments are increased. The instantaneous and convex closing laws give rise to minimum and maximum pressure, respectively.
\end{abstract}

\section{Introduction}

Most analysis of flow in pipelines and networks has assumed the flow to be at steady state conditions. This means that the flow does not change with time at any location in the pipeline system. With the assumption of uniform flow, the analysis becomes simpler and solutions are easy to obtain. Study on transient condition is important because pipeline flows are frequently in unsteady state due to the sudden opening and closing of valves. All transient flows are transitions, whether in long or short duration. Transient flow can be defined as the flow fluctuation when the velocity and pressure of a fluid or gas flow change over time due to changes in the system. Relating specifically to pressure, they are sometimes called dynamic pressure changes or pressure transients.

It is not feasible to prevent pressure transient when operating a piping system, but this situation can be controlled. The main causes of transient flow conditions are closing or opening of valves in the piping system, switching off the power supply, or a power failure and/or equipment failure. The sudden closure of a control valve, stopping of a pump, and variation of discharge due to pipeline rupture lead to excess pressure in a pipeline [1]. Wood et al. [2] stated that the pressure transient results from an abrupt change in the flow velocity and can be caused by main breaks, sudden changes in demand, or uncontrolled pump starting.

When velocities in a pipe system change so rapidly that the elastic properties of the pipe and the liquid or gas must be examined in an analysis, we have a hydraulic transient commonly known as water hammer. Water hammer is a kind of transient phenomenon that occurs when rapid valve closure suddenly blocks the flow in pipelines. It depends on the fluid compressibility where there are sudden changes in pressure. Understanding water hammer is very important in order to prevent excessive pressure buildup in pipelines which cause pipeline damage [3].

Pressure change in pipelines depends on gas velocity, valve closure time [4], and arrangement of the closing valve. Maximum pressure can occur during valve closure or at the end of the closure operation. Therefore, short times during valve closure are important in reducing the maximum pressure, especially in emergency conditions. Unfortunately, this pressure transient is difficult to control because this damage is not always visible until long after the event. 
Therefore, valves are always installed in the pipeline to control the gas flow when damage occurs.

According to Provenzano et al. [5], there are four methods which can be used to modify the action of the valve (closure law), most commonly referred to as convex, concave, linear, and instantaneous closing law. These types of closing valve laws represent a mathematical function that describes the speed variation of the flow as it is closing. These types of valve closure depend on the rate at which valves can be closed. The valve closure rate plays an important role in controlling the water hammer phenomenon [1].

Valve closure times are also a source of risk when we analyse the water hammer phenomenon. Thus, some efforts have been expended to optimize the time closure of control valves, taking into account several kinds of restrictions. Ghidaoui et al. [6] presented a general history and introduction of the water hammer phenomenon. They stated that the problem of water hammer was first studied by Menabrea [7]. Michaud [8] examined the use of air chambers and safety valves for controlling water hammer. In the early 19 th century, some researchers attempted to develop expressions relating to pressure and velocity changes in a pipe.

Afshar et al. [1] developed a closing rule curve for valves in pipelines to control the water hammer impact. They predicted the pressure increase and pipe discharge for a valve closing scenario in fluid flow. The effect of different parameters such as velocity, viscosity, and compressibility of the pressure was investigated by Charles [9]. Fouzi and Ali [10] studied the effects of water hammer in hydraulic systems. Mansuri et al. [11] also studied the sensitivity of some hydraulic parameters to water hammer problem. These four types of closure laws have been considered mostly in fluids involving water but have not yet been applied in hydrogennatural gas mixture.

Elaoud and Hadj-Taïb [12] studied the transient flow in hydrogen-natural gas mixture. Studies on such problems are important because hydrogen is usually transported in the same pipeline as natural gas to reduce transportation cost and hydrogen is often stored together with natural gas to enhance its storage capability. However, they seemed to have considered only the linear closing valve to determine the relationship between the mass ratio of mixture and pressure.

According to Fouzi and Ali [10], analytical solutions are not possible in the field of those who study the hydraulic transient. Allievi [13] developed classical solutions for both analytical and graphical approaches. Streeter [14] developed a numerical model by using a constant value of the turbulent friction factor. Wiggert and Sundquist [15] solved the pipeline transients using fixed grids projecting the characteristics from outside the fundamental grid size. Watt et al. [16] provided a solution for rise of pressure by the method of characteristics, but transient friction has not been considered. Chaudhry and Hussaini [17] solved the water hammer equations by MacCormack, Lambda, and Gabutti explicit finite difference schemes. Pezzinga [18] and Elaoud and Hadj-Taïeb [12] worked to evaluate the transient flow resistance by the method of characteristics.

Various numerical models including the Method of Characteristics (MOC) and Finite Difference Method (FDM) have been presented by different investigators to obtain the transient pressure and discharge in water hammer situations. However, these methods are time consuming, especially for gas network analysis. More accurate results and lower computational costs are needed for the simulation of gas network analysis. Behbahani-Nejad and Shekari [19, 20] proposed a Reduced Order Model (ROM) approach to achieve an efficient computational scheme for natural gas transient pipe flows. ROM gave lower computational cost and reduced time for computation. ROM was recently used in the analysis of unsteady flows [21]. Agaie and Amin [22] used the ROM technique to study the effect of water hammer on transportation of hydrogen-natural mixture. They validated the Provenzano et al. [5] problems to verify the accuracy of ROM.

In the present study, the water hammer phenomenon will be solved by using this ROM on transient flow of hydrogennatural gas mixture. Our main objective is to determine the relationship between the pressure waves of hydrogen-natural gas mixture with different modes of closing and opening of valves, most commonly referred to as convex, concave, linear, and instantaneous closing law. To verify our objective, the water hammer on transient flow of hydrogen-natural gas is analysed based on the types of closing laws, closure valve times, and the number of polygonal segments in the closing function.

\section{Mathematical Formulation}

The mathematical models used to describe unsteady flows of hydrogen-natural gas mixture in horizontal pipelines are presented in the following.

2.1. Governing Equation. From the principle of conservation of mass and momentum laws, the governing equations for the transportation of hydrogen-natural gas mixture in pipelines are given by

$$
\begin{gathered}
\frac{\partial \rho}{\partial t}+\nabla \cdot(\rho \mathbf{V})=0 \\
\frac{\partial(\rho \mathbf{V})}{\partial t}+\nabla \cdot(\rho u \mathbf{V})=-\nabla P+\nabla \tau_{w}+\rho \mathbf{F},
\end{gathered}
$$

where $\rho$ is defined as density, $\mathbf{V}$ is vector velocity, $u$ is gas velocity, $P$ is pressure, $\tau_{w}$ is shear force, and $\mathbf{F}$ is the net body force per unit mass.

For a one-dimensional flow, the continuity and momentum equation under isothermal conditions can be written as

$$
\begin{gathered}
\frac{\partial \rho}{\partial t}+\frac{\partial(\rho u)}{\partial x}=0 \\
\frac{\partial(\rho u)}{\partial t}+\frac{\partial\left(\rho u^{2}\right)}{\partial x}=-\frac{\partial P}{\partial x}+\nabla \tau_{x}+\rho f_{x}
\end{gathered}
$$

where $\tau_{x}$ is the shear force in the $x$-direction and $f_{x}$ is the net body force per unit mass.

Using the hydraulic mean diameter $D$, the perimeter of the pipe can be defined as $4 / D$. The shear force may be 
expressed in terms of the pipe friction coefficient $f^{\prime}=$ $\tau_{x} /(1 / 2) \rho u^{2}$, which can then be expressed as

$$
\tau_{x}=-\frac{1}{2} f^{\prime} \rho u^{2} \times \frac{4}{D}=\frac{2 f^{\prime} \rho u^{2}}{D} .
$$

Substituting (4) into (3), the one-dimensional momentum equation in horizontal pipelines becomes

$$
\frac{\partial(\rho u)}{\partial t}+\frac{\partial\left(\rho u^{2}\right)}{\partial x}=-\frac{\partial P}{\partial x}-\frac{2 f^{\prime} \rho u^{2}}{D} .
$$

According to Chaczykowski [23], the form of friction factor $2 f^{\prime} \rho u^{2} / D$, where $f^{\prime}=f / 4$, is only used in the United Kingdom. This friction factor $f$ is called the Fanning friction factor which is defined as the ratio of the pipeline wall shear stress to the roughness of the pipe. When this Fanning friction factor is applied, the momentum equation in (5) can also be expressed as

$$
\frac{\partial(\rho u)}{\partial t}+\frac{\partial\left(\rho u^{2}\right)}{\partial x}=-\frac{\partial P}{\partial x}-\frac{f \rho u^{2}}{2 D} .
$$

The form of the friction term $-f \rho u^{2} / 2 D$ in (6) is more frequently used in America and Europe. However, to ensure that the frictional force shall always act opposite to the direction of motion, the momentum equation is written as

$$
\frac{\partial(\rho u)}{\partial t}+\frac{\partial\left(\rho u^{2}+P\right)}{\partial x}+\frac{f \rho u|u|}{2 D}=0 .
$$

2.2. Equation of State. For the isothermal flow in a pipeline, the gas properties can be assumed to be uniform or constant over any cross section in a pipeline. It is known that the static pressure may be assumed to be constant over a cross section of the pipeline. Isothermal flow means that the gas remains at the same temperature while flowing in a pipeline [24]. The equation of state for gas, which is commonly used in the gas industry, is given by

$$
\frac{P}{\rho}=Z R T
$$

where $Z$ is the compressibility factor, $R$ is the specific gas constant, and $T$ is the constant temperature.

Usually the compressibility factor $Z$ is assumed to be constant too [20]. Then, the relation between the equation of state with celerity pressure wave $c$ is given by

$$
P=\rho c^{2}
$$

The momentum equation (7) becomes written in terms of the celerity pressure wave:

$$
\frac{\partial(\rho u)}{\partial t}+\frac{\partial\left(\rho u^{2}+\rho c^{2}\right)}{\partial x}+\frac{f \rho u|u|}{2 D}=0 .
$$

Therefore, the continuity equation (2) and momentum equation (10) will be used in transient analysis of isothermal hydrogen-natural gas mixture in horizontal pipeline.
2.3. Closing Valve Law Equation. The closing valve law is a mathematical function that describes the speed variation of the gas flow as it is closing [5]. The derivative of (9) is taken and the subscript $s$ denotes the condition of constant entropy given by

$$
c^{2}=\left(\frac{\partial P}{\partial \rho}\right)_{s} .
$$

From (11), the relation of pressure and density to function of $t$ and $x$ can be written as

$$
\begin{aligned}
& \frac{\partial \rho}{\partial t}=\frac{1}{c^{2}} \frac{\partial P}{\partial t} \\
& \frac{\partial \rho}{\partial x}=\frac{1}{c^{2}} \frac{\partial P}{\partial x}
\end{aligned}
$$

Substituting (12a) and (12b) into (2) and (10) yields

$$
\begin{array}{r}
\frac{\partial P}{\partial t}+\rho c^{2} \frac{\partial u}{\partial x}=0 \\
\frac{\partial u}{\partial t}+\frac{1}{\rho} \frac{\partial P}{\partial x}+\frac{f u|u|}{2 D}=0
\end{array}
$$

In many cases on closing valve in pipes, the friction factor is negligible because the value is very small. Differentiating equations (13a) and (13b) with respect to $t$ and $x$, respectively, gives

$$
\begin{gathered}
\frac{\partial^{2} P}{\partial t^{2}}+\rho c^{2} \frac{\partial}{\partial t}\left(\frac{\partial u}{\partial x}\right)=0 \\
\frac{\partial}{\partial x}\left(\frac{\partial u}{\partial t}\right)+\frac{1}{\rho} \frac{\partial^{2} P}{\partial x^{2}}=0
\end{gathered}
$$

Substituting (14a) and (14b) into one-dimensional wave equation gives the continuity and momentum equation which described the pattern of closing valve function as

$$
\begin{aligned}
\frac{1}{c^{2}} \frac{\partial^{2} P}{\partial t^{2}} & =-\rho \frac{\partial}{\partial t}\left(\frac{\partial u}{\partial x}\right), \\
\frac{\partial^{2} P}{\partial x^{2}} & =-\rho \frac{\partial}{\partial x}\left(\frac{\partial u}{\partial t}\right) .
\end{aligned}
$$

2.4. Hydrogen-Natural Gas Mixture Equation. For hydrogennatural gas mixture, the hydrogen mass ratio will be used in determining the mixture density, where the mass ratio of the mixture is described as

$$
\phi=\frac{m_{h}}{m_{h}+m_{g}},
$$

where $m_{g}$ and $m_{h}$ are defined as the mass of natural gas and hydrogen, respectively.

The density of hydrogen and natural gas can be defined as

$$
\begin{aligned}
& \rho_{h}=\rho_{h_{0}}\left(\frac{P}{P_{0}}\right)^{1 / n}, \\
& \rho_{g}=\rho_{g_{0}}\left(\frac{P}{P_{0}}\right)^{1 / n^{\prime}},
\end{aligned}
$$


where $\rho_{h_{0}}$ and $\rho_{g_{0}}$ are initial density of hydrogen and natural gas, respectively, $P$ is transient pressure, and $P_{0}$ is permanent pressure.

The expression of the average density of the mixture is defined according to the mass ratio, $\phi$. The density of the hydrogen-natural gas mixture then can be written as

$$
\begin{aligned}
\rho & =\left[\frac{\phi}{\rho_{h}}+\frac{(1-\phi)}{\rho_{g}}\right]^{-1} \\
& =\left[\frac{\phi}{\rho_{h_{0}}}\left(\frac{P}{P_{0}}\right)^{1 / n}+\frac{(1-\phi)}{\rho_{g_{0}}}\left(\frac{P}{P_{0}}\right)^{1 / n^{\prime}}\right]^{-1} .
\end{aligned}
$$

From (11), the celerity pressure wave of compressible gas flow can be expressed based on the hydrogen mass ratio. By taking the derivative of (18) with respect to $P$, the celerity pressure wave (11) can be written as

$$
\begin{aligned}
c= & {\left[\frac{\phi}{\rho_{h_{0}}}\left(\frac{P}{P_{0}}\right)^{1 / n}+\frac{(1-\phi)}{\rho_{g_{0}}}\left(\frac{P}{P_{0}}\right)^{1 / n^{\prime}}\right] } \\
& \times\left[\frac{1}{P}\left\{\frac{\phi}{n \rho_{h_{0}}}\left(\frac{P}{P_{0}}\right)^{1 / n}+\frac{(1-\phi)}{n^{\prime} \rho_{g_{0}}}\left(\frac{P}{P_{0}}\right)^{1 / n^{\prime}}\right\}\right]^{-(1 / 2)} .
\end{aligned}
$$

2.5. Closing Valve Function. Provenzano et al. [5] proposed the following closing function:

$$
u(t)=\left(u_{0}-u_{\tau}\right)\left[1-\left(\frac{t}{\tau}\right)^{m}\right]+u_{\tau}
$$

where $\tau=N k$ is the closing time, $0 \leq m<\infty$, and $u_{\tau}$ is the gas speed at the end of the closing valve.

The closing time $(\tau)$ is stepped by a number of polygonal segments in closing function denoted by $k$ given by

$$
u_{i}=\left(u_{0}-u_{\tau}\right)\left[1-\left(\frac{i k}{\tau}\right)^{m}\right]+u_{\tau},
$$

where $0 \leq i \leq N$.

Equation (20b) allows finding the speed values at each of the stepped times $i k$.

2.6. Boundary Conditions. The boundary conditions at the initial point, $x=0$, are given by

$$
\begin{gathered}
P(0, t)=P_{0}(t), \\
\rho(0, t)=\rho_{0}(t), \\
\frac{\partial u}{\partial x}(0, t)=u_{0}(t),
\end{gathered}
$$

where $P_{0}, \rho_{0}$, and $u_{0}$ are defined as pressure, density, and velocity at the inlet pipeline, respectively.

The boundary conditions at the end point $x=L$ are

$$
\begin{aligned}
& \rho u(L, t)=\rho u_{L}(t), \\
& \frac{\partial P}{\partial x}(L, t)=P_{L}(t),
\end{aligned}
$$

where $\rho u_{L}$ and $P_{L}$ are defined as mass flux and pressure at the outlet pipeline, respectively.

2.7. Initial Conditions. The initial conditions at $t=0$ are

$$
\begin{aligned}
\frac{\partial \rho}{\partial x}(x, 0) & =0 \\
\frac{\partial \rho u}{\partial x}(x, 0) & =-c^{2} \frac{\partial \rho}{\partial x}-\frac{f \rho u|u|}{2 D} .
\end{aligned}
$$

\section{Numerical Solution}

To solve numerically the governing equations (2) and (10), Reduced Order Model (ROM) is used. The ROM is an efficient method to solve the transient hydrogen-natural gas mixture in a gas pipeline because of smaller number of errors and reduced time consumption and computational cost.

3.1. Transformation of Flux Vector Form. The governing equations (2) and (10) can be written in the flux vector form:

$$
\frac{\partial Q}{\partial t}+\frac{\partial E(Q)}{\partial x}-H(Q)=0
$$

where

$$
\begin{gathered}
Q=\left[\begin{array}{c}
\rho \\
\rho u
\end{array}\right], \\
E(Q)=\left[\begin{array}{c}
\rho u \\
\rho u^{2}+c^{2} \rho
\end{array}\right], \\
H(Q)=\left[\begin{array}{c}
0 \\
-\frac{f \rho u|u|}{2 D}
\end{array}\right] .
\end{gathered}
$$

3.2. Discretization of Implicit Steger Warming Flux Vector Splitting Scheme. To construct ROM, Implicit Steger Warming Flux Vector Splitting Scheme (FSM) will be applied. Finite Difference Method (FDM) will be used to discretize equation (23) and to obtain FSM scheme. By using this FSM, the eigenvalue problem will be constructed from (23). The resulting FSM scheme can be written as

$$
\begin{gathered}
-\left[\frac{\Delta t}{\Delta x} A_{i-1}^{n(+)}\right] \Delta Q_{i-1}+\left[\frac{\Delta t}{\Delta x} A_{i+1}^{n(-)}\right] \Delta Q_{i+1} \\
+\left[I+\frac{\Delta t}{\Delta x}\left(A_{i}^{n(+)}-A_{i}^{n(-)}\right)-\Delta t B_{i}^{n}\right] \Delta Q_{i} \\
=-\frac{\Delta t}{\Delta x}\left[E_{i}^{n(+)}-E_{i-1}^{n(+)}+E_{i+1}^{n(-)}-E_{i}^{n(-)}\right]+\Delta t H_{i}^{n} .
\end{gathered}
$$

3.3. Form of Eigenvalues Problem. To perform the eigenanalysis and construct ROM, it is necessary to linearize the finite difference equation in (25) [19]. The linearization can be achieved by assuming steady state in which stability perturbation is used to obtain the transient solution at each nodal point. 
For linearization, the flow field variables at each time step are given by

$$
Q^{n+1}=Q^{0}+\widehat{Q}^{n+1},
$$

where $Q^{0}$ represents the corresponding steady-state values and $\widehat{Q}$ represents perturbation values.

Substituting (26) into (25) yields

$$
\begin{aligned}
& -\left[\frac{\Delta t}{\Delta x} A_{i-1}^{0(+)}\right] \widehat{Q}_{i-1}^{n+1}+\left[\frac{\Delta t}{\Delta x} A_{i+1}^{0(-)}\right] \widehat{Q}_{i+1}^{n+1} \\
& \quad+\left[I+\frac{\Delta t}{\Delta x}\left(A_{i}^{0(+)}-A_{i}^{0(-)}\right)\right] \widehat{Q}_{i}^{n+1}-\Delta t B_{i}^{0} \widehat{Q}_{i}^{n+1} \\
& =\widehat{Q}_{i}^{n} .
\end{aligned}
$$

Equation (27) can be simplified in the form of eigenvalue problem:

$$
W^{0} \widehat{Q}^{n+1}=I \widehat{Q}^{n}+V^{n+1},
$$

where $V^{n+1}=-\left[(\Delta t / \Delta x) A_{i-1}^{0(+)}\right] \widehat{Q}_{i-1}^{n+1}+\left[(\Delta t / \Delta x) A_{i+1}^{0(-)}\right] \widehat{Q}_{i+1}^{n+1}$ and $V$ is defined as a vector consisting of the imposed values by the boundary conditions and $W^{0}$ represents the matrix.

3.4. Construction of Reduced Order Model. To construct the ROM technique, the zero eigenvalue in the eigensystem of matrix is required. For zero forcing function $V$, we need to consider the homogeneous part of (28) by setting

$$
\widehat{Q}_{i}=x_{i} \exp \left(i \omega_{i} t\right) \alpha_{i} \exp \left(i z_{i} x\right),
$$

where $\lambda_{i}$ is defined as eigenvalues, $x_{i}$ is eigenvector, and $z_{i}=$ $\exp \left(\lambda_{i} \Delta t\right)$.

Then, the diagonal matrix which contains the eigenvalues and eigenvector can be written as

$$
z_{i} W^{0} x_{i}=I x_{i} .
$$

In general, (30) can be written as

$$
Z W^{n} X=I X,
$$

where $Z$ represents the diagonal matrix of eigenvalue at each time step and $X$ is the matrix with column representing the right eigenvector.

On the other hand, the left eigenvectors satisfy the following relation:

$$
\left(W^{0}\right)^{T} Y Z=I Y
$$

where $Y$ is the matrix with rows that represent the left eigenvector.

If the eigenvectors are suitably normalized, they satisfy the following orthogonality conditions:

$$
\begin{aligned}
Y^{T} W^{n} X & =I, \\
Y^{T} I X & =Z .
\end{aligned}
$$

3.5. Eigenmode Analysis. For analysis of eigenmode based on time, (29) reduces the gas flow behavior to the sum of individual nodes:

$$
\widehat{Q}_{i}=x_{i} \exp \left(\lambda_{i} t\right) .
$$

Equation (34) can be written in general form as

$$
\widehat{Q}=X \widehat{c},
$$

where $\widehat{c}$ is the vector of normal node coordinate.

Substituting (33) and (28) and then multiplying by $Y^{T}$ give a set of $N$ uncoupled equations for the nodal coordinates $\widehat{c}$ :

$$
\hat{c}^{n+1}=Z \widehat{c}^{n}+Y^{T} V^{n+1} .
$$

Since the orthogonality conditions are satisfied, the eigenmode can be retained to construct ROM using (36).

\section{Results and Discussion}

Before analyzing the effect of different types of closing valve, the simple case of fluid (water) flow will be validated according to Provenzano et al. [5] problem. In the present study, ROM is used as numerical method to solve the governing equations (2) and (10). This current method is used to validate the results.

Figure 1 shows the results from the current method compared to those obtained by an analytical method. The results obtained using ROM are in good agreement with those of the analytical solution. The effect of water hammer is observed at pressure oscillation at different types of closing laws as plotted in Figure 1.

4.1. Effect of Different Types of Closing Valve: Case Study 1. Four different types of closing valve laws are used to test the accuracy of the solution in case of transient flow of hydrogennatural gas mixture occurring in the pipeline.

A single horizontal pipeline composed of a compressor pumping the mixture through an iron pipe and characterized by a section of a pipeline system of $L=500 \mathrm{~m}$ length and $D=0.4 \mathrm{~m}$ in diameter is illustrated in Figure 2. A rapid closure valve (RCV) is placed at the downstream end, whereas the automatic closure valve (ACV) is placed at the immediate discharged side of the compressor to avoid destruction of the compressor [12].

Two parameters are used to characterize the dynamic response of the valves which are the reaction time and actuation time. The reaction time is defined as the time taken to start the valve actuation after sensing a pressure perturbation, while the actuation time is the time interval between the initial and the final positions of the valve. The actuation time is only considered for the RCV side.

Four types of closing valve laws which are classified into instantaneous, concave, linear, and convex are considered. Figure 3 shows the closing function corresponding to the different types of closing valve with different mass ratio of hydrogen-natural gas mixture. The $m$ exponent in (20a) determines the closing curve function as follows: 


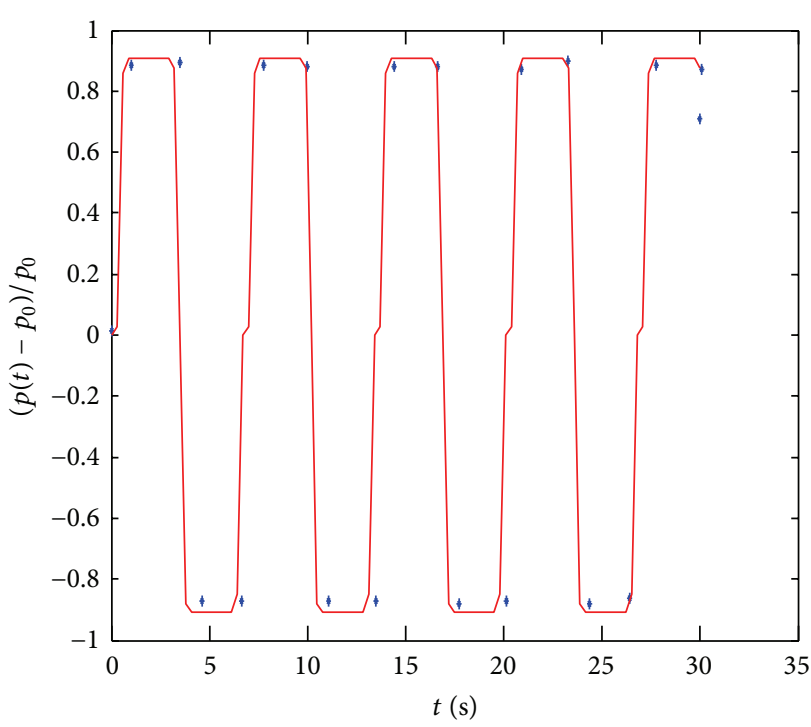

- Provenzano et al. (2011)

— Present method

(a) Instantaneous closing valve law $(m=0)$

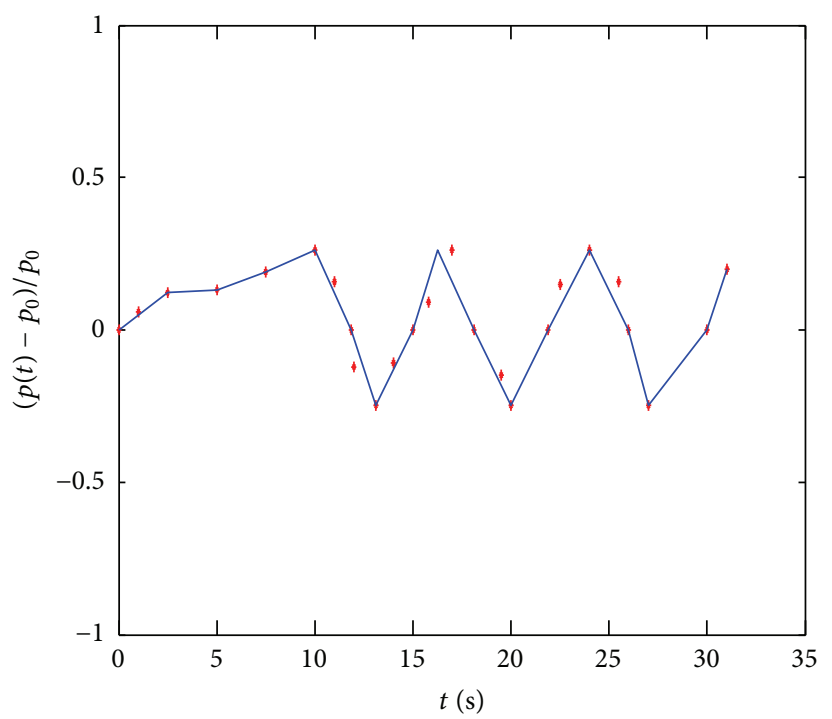

- Provenzano et al. (2011)

— Present method

(c) Linear closing valve law $(m=1)$

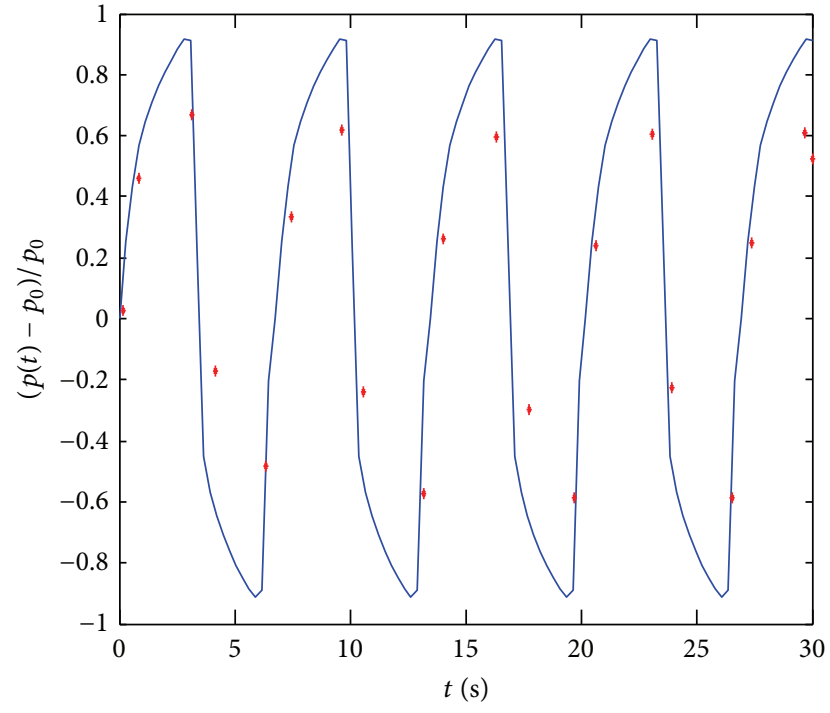

— Present method

- Provenzano et al. (2011)

(b) Concave closing valve law $(m=0.3)$

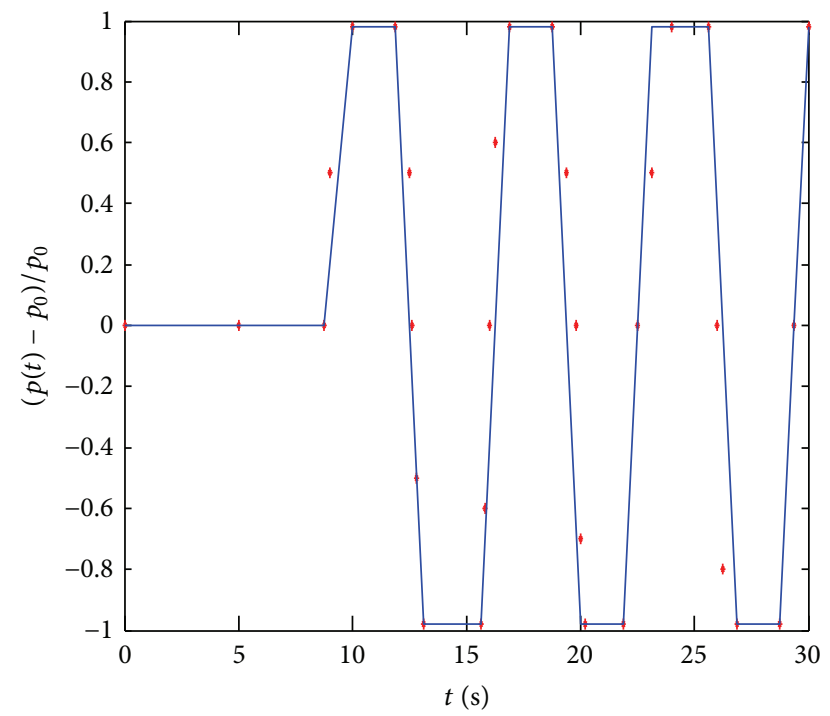

- Provenzano et al. (2011)

— Present method

(d) Convex closing valve law ( $m=48)$

FIGURE 1: Transient pressure waves for different types of closing valve laws (comparison present method (ROM) with analytical method) [5].

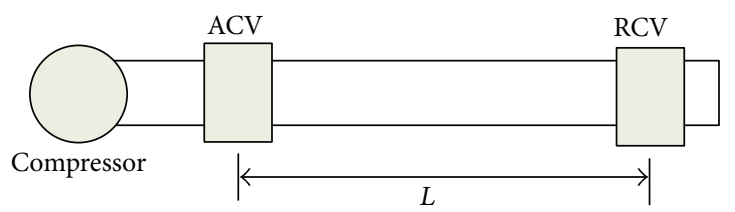

FIGURE 2: Hydrogen-natural gas mixture installation [12]. 


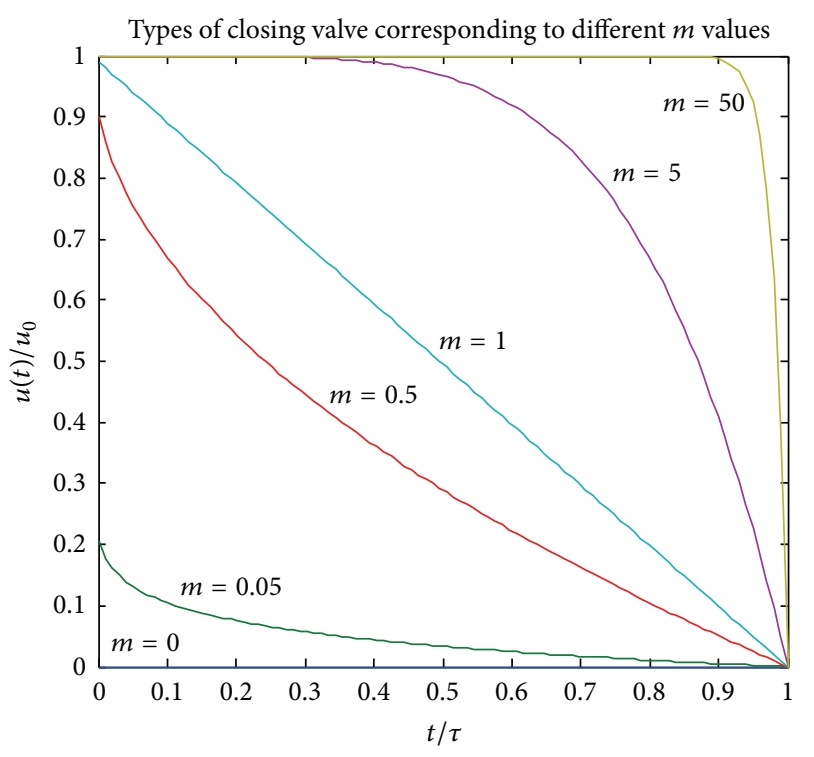

FIGURE 3: Closing function corresponding to different values of $m$ (from (20a)).

$$
\begin{aligned}
& m=0 \text { instantaneous closing; } \\
& 0 \leq m<1 \text { concave closing; } \\
& m=1 \text { linear closing; } \\
& 1 \leq m<\infty \text { convex closing. }
\end{aligned}
$$

For instantaneous closing valve, the gas flow speed changes instantly to zero. The speed of gas flow is reduced uniformly during the whole closing time when the linear closing valve is applied. Concave closing valve demonstrates rapid decrease of the speed flow at initial closing time and then a slow reduction for most of the time, whereas convex closing valve features a low decrease of the speed flow during the early closing time which increases with time.

Figure 4 shows plots of the numerically obtained results for the pressure wave distribution as a function of time for different values of the hydrogen mass ratio $\phi$. The numerical results clearly show the interaction of the pressure wave generated by the types of closing valve. The results of the numerical simulation, plotted in Figure 4, show that the pressure wave oscillation is repeated every $7 \mathrm{~s}$ for each type of closing law.

For instantaneous closing law, the maximum pressure wave for hydrogen is 20.06 bar; for hydrogen-mixture (67\%), the maximum pressure wave is 20.05 bar; for hydrogenmixture (33\%), the maximum pressure wave is 20.03 bar; and for natural gas, the maximum pressure wave is $20.01 \mathrm{bar}$. From these numerical results, the transient pressure wave of hydrogen and hydrogen-natural gas mixture are much higher compared to natural gas. For concave, convex, and linear closing valves, hydrogen has a maximum value of pressure wave compared to natural gas. Instant closing valve produces the minimum values of pressure waves compared to concave, convex, and linear closing valve.

Figure 4 gives information on the pressure wave profile as a function of the closing valve. The shape of pressure wave changes from square to trapezoidal for instantaneous
TABLE 1: Closure times [12].

\begin{tabular}{lccc}
\hline Test & ACV reaction $(\mathrm{s})$ & ACV actuation $(\mathrm{s})$ & RCV actuation $(\mathrm{s})$ \\
\hline 1 & 2 & 5 & 0.25 \\
2 & 0.2 & 0.5 & 0.2 \\
\hline
\end{tabular}

closing law. For concave closing law $(0<m<0.5)$, the pressure wave shape changes to trapezoidal. When the value of $m$ increases $(0.5<m<1)$ the pressure wave shape is changed to triangular. For linear closing law, the pressure wave presented a strictly triangular form. For convex closing law (5<m<50), the pressure wave changes from triangular towards the trapezoidal shape and becomes pulse when $(50<m<\infty)$. This pulse wave is a kind of nonsinusoidal wave form that is similar to a square wave but does not have the symmetrical shape associated with a perfect square wave. However, increasing the values of $m$ will increase the computation time and pressure wave.

4.2. Effect of Closing Times: Case Study 2. In case study 2, the effects of the pressure change can be demonstrated by varying the valve closure times [25]. Two tests of different valve closure times are considered. Table 1 summarizes these closure times.

Figure 5 shows the effects of different valve closing times on the transient pressure wave for hydrogen-natural gas mixture $(33 \%)$. Four different valves are considered for the purpose of simulating the results. The numerical results clearly show the interaction of the pressure wave generated by RCV with the closure time of ACV [12]. From the results plotted in Figure 5, the maximum value of the pressure wave is 20.02 bar for Test 1 , which is reached $0.25 \mathrm{~s}$ after the valve closed instantly. This higher pressure may be lowered by reducing the closure time which is represented by Test 2 . 


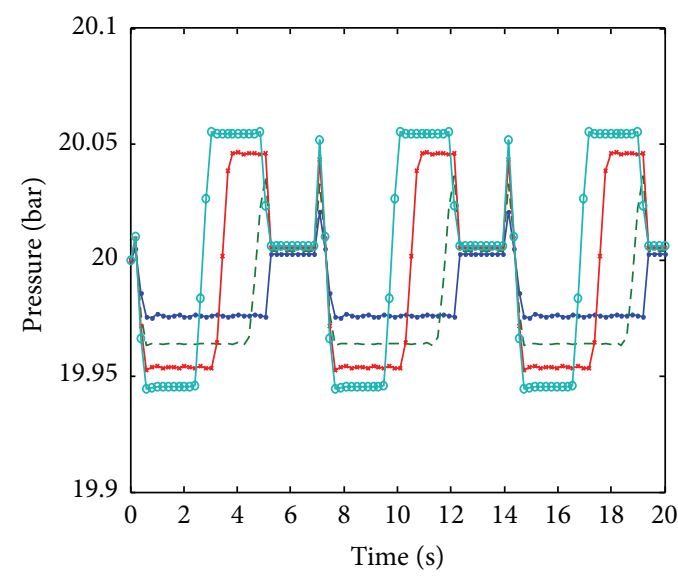

(a) Instantaneous closing valve law $(m=0)$

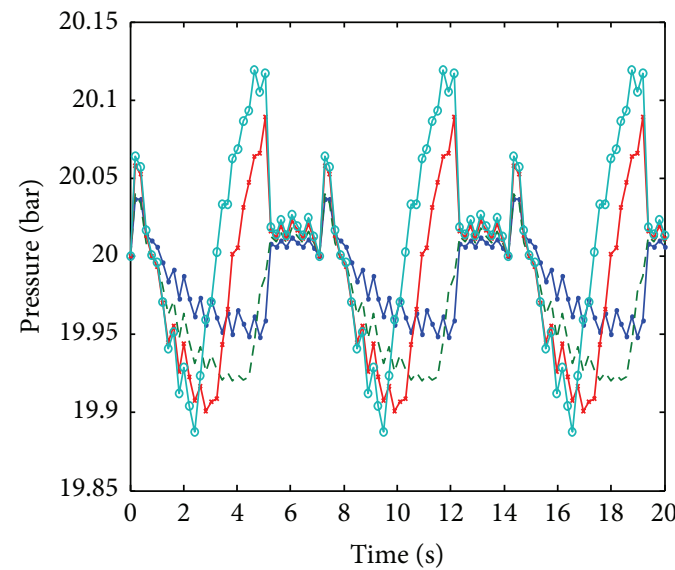

(c) Concave closing valve law $(m=0.5)$

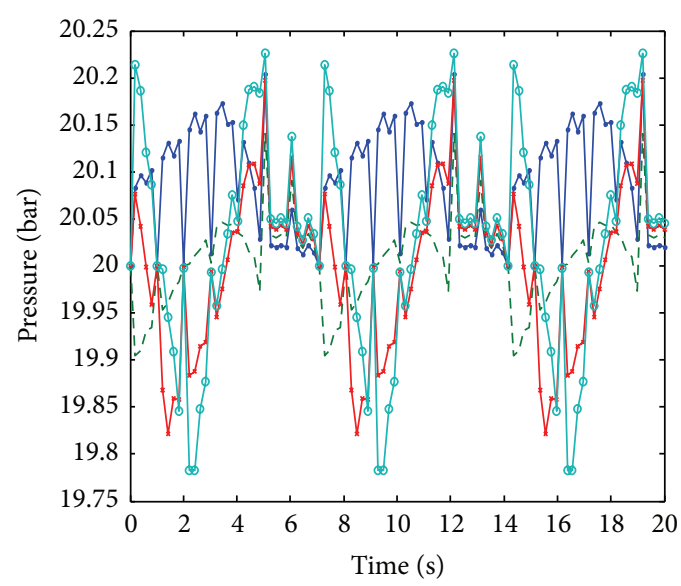

- - - Hydrogen mixture (33\%) $\rightarrow$ Hydrogen

$\rightarrow$ Hydrogen mixture (67\%) $\rightarrow$ Natural gas

(e) Convex closing valve law $(m=5)$

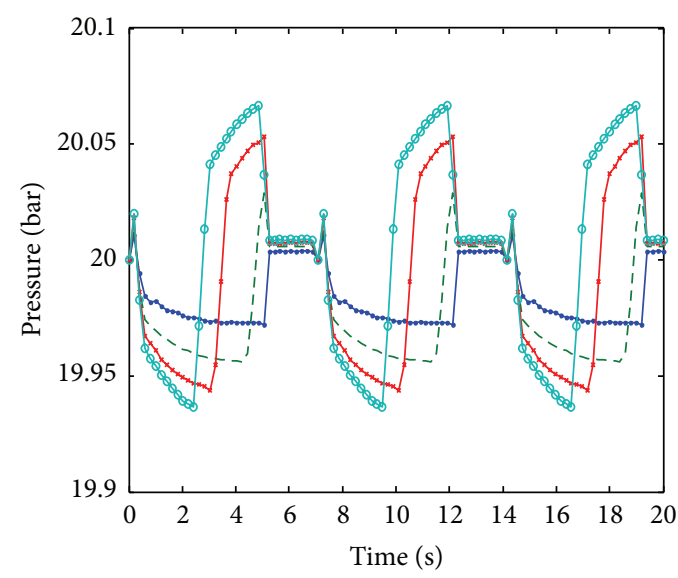

(b) Concave closing valve law $(m=0.05)$

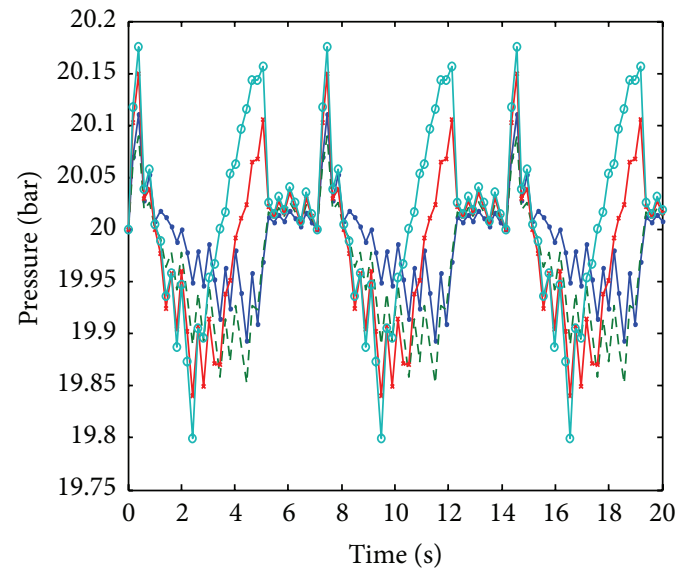

(d) Linear closing valve law $(m=1)$

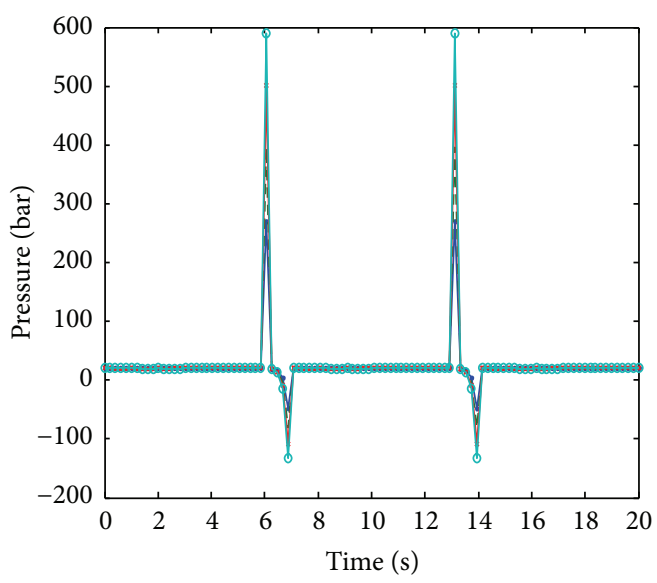

- - - Hydrogen mixture (33\%) $\rightarrow$ Hydrogen

$\rightarrow$ Hydrogen mixture $(67 \%) \rightarrow$ Natural gas

(f) Convex closing valve law $(m=50)$

FIGURE 4: Transient pressure waves for different types of closing valve laws at different mass ratio. 


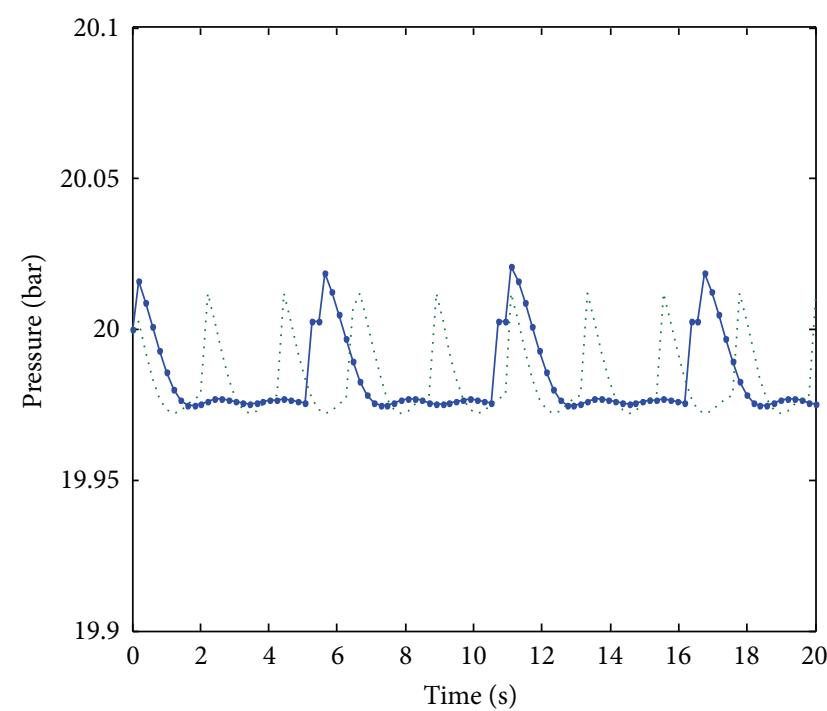

(a) Instantaneous closing valve law $(m=0)$

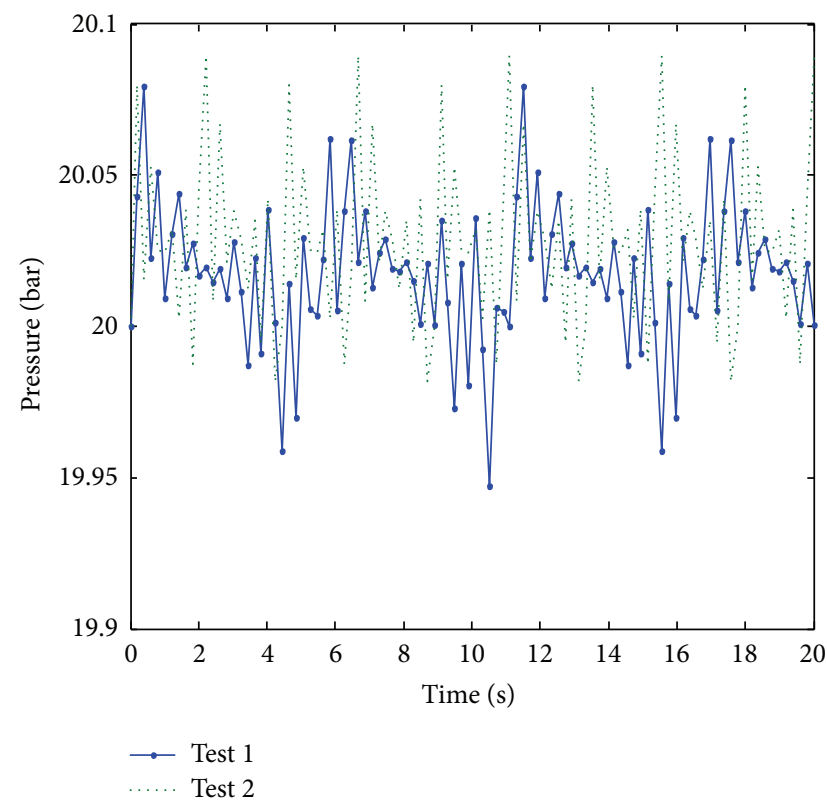

(c) Linear closing valve law $(m=1)$

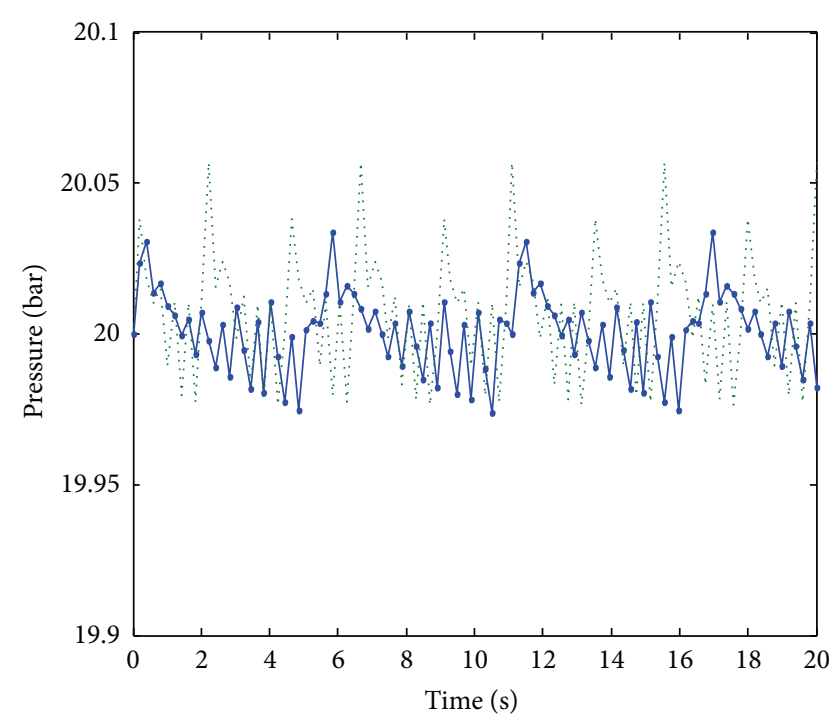

(b) Concave closing valve law $(m=0.5)$

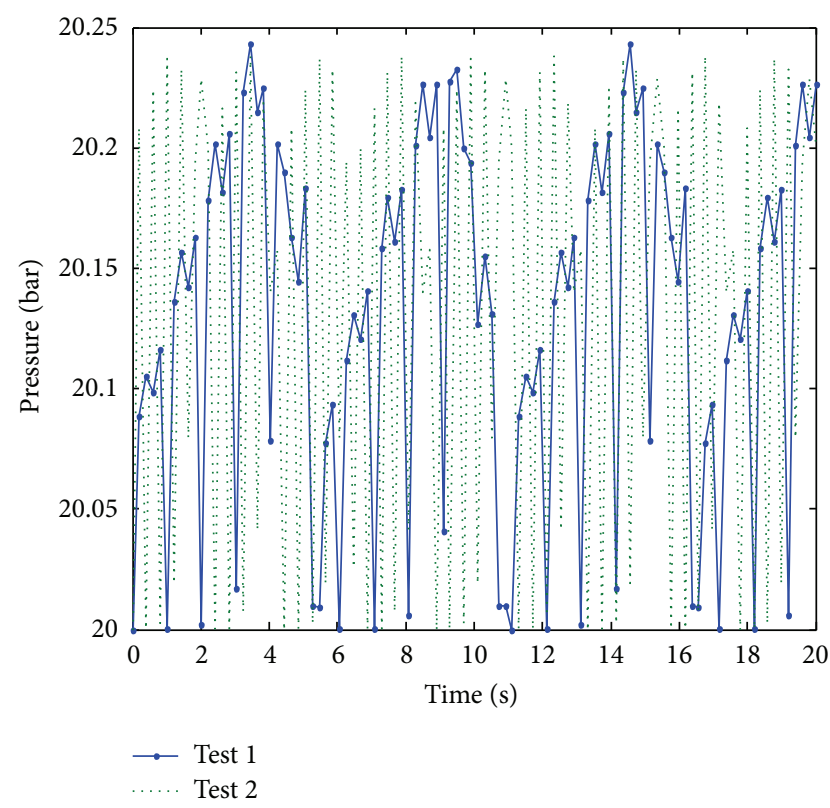

(d) Convex closing valve law $(m=5)$

FIGURE 5: Transient pressure waves as function of time, 33\% mass ratio of hydrogen-natural gas mixture.

In this case, the maximum value of the pressure wave is reduced to the value of $20.01 \mathrm{bar}$, which is reached in $2.25 \mathrm{~s}$ after the valve is closed. For convex valve, the maximum value of pressure wave for Test 1 is 20.24 bar, reached in $3.00 \mathrm{~s}$ after the valve closed, and the maximum value of pressure wave for Test 2 is reduced to 20.22 bar, which is reached $1.00 \mathrm{~s}$ after the valve is closed.

However, for concave and linear closing valve, decreasing the valve closing time shows an increasing pressure wave [25]. For concave valve, the maximum value of pressure wave of Test 1 and Test 2 is 20.03 bar and 20.05 bar, which reached $6.00 \mathrm{~s}$ and $2.25 \mathrm{~s}$, respectively. For linear valve, the maximum value of pressure wave of Test 1 is 20.08 bar at $0.05 \mathrm{~s}$ and
20.09 bar at $2.25 \mathrm{~s}$ for Test 2. From the numerical results, increasing the values of $m$ will increase the pressure wave for both closing times. Closing the valve instantly takes less time to reduce the pressure compared to the convex closing law that takes more time to reduce the pressure.

4.3. Effect of Number of Polygonal Segments in the Closing Function: Case Study 3. For case study 3, the effect of number of polygonal segments in the closing function has been evaluated at different types of closing valves. Three different polygonal segments denoted by $k(k=2,4,10)$ have been tested to describe the profile and amplitude of pressure waves at $33 \%$ of hydrogen-natural gas mixture. 


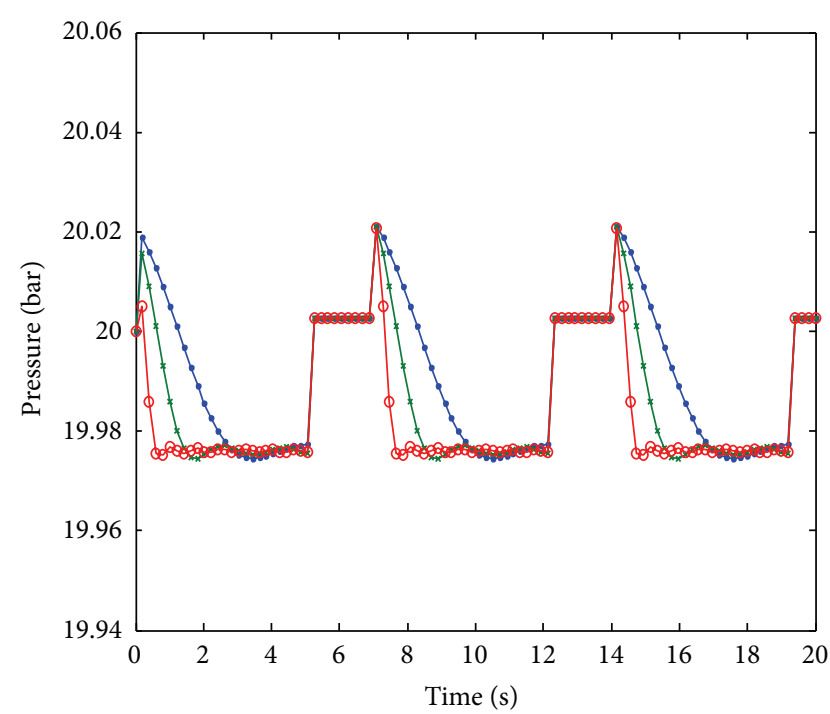

(a) Instantaneous closing valve law $(m=0)$

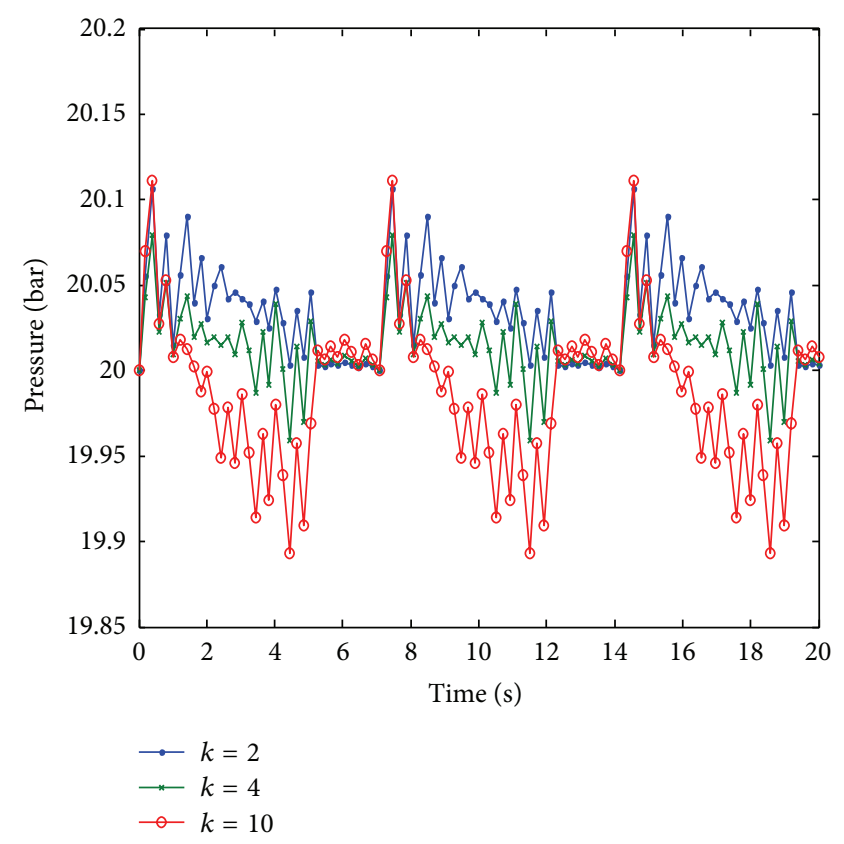

(c) Linear closing valve law $(m=1)$

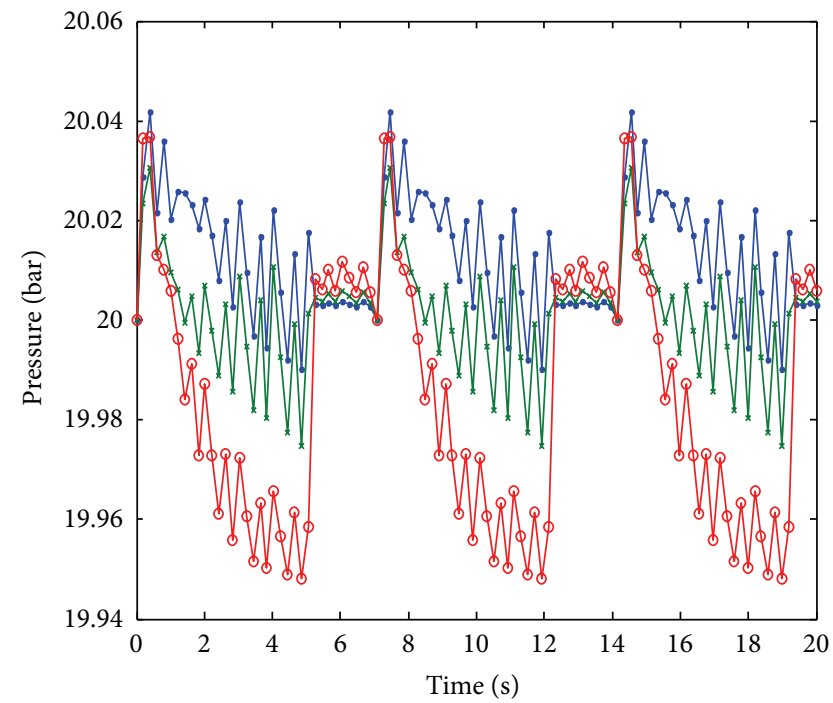

(b) Concave closing valve law $(m=0.5)$

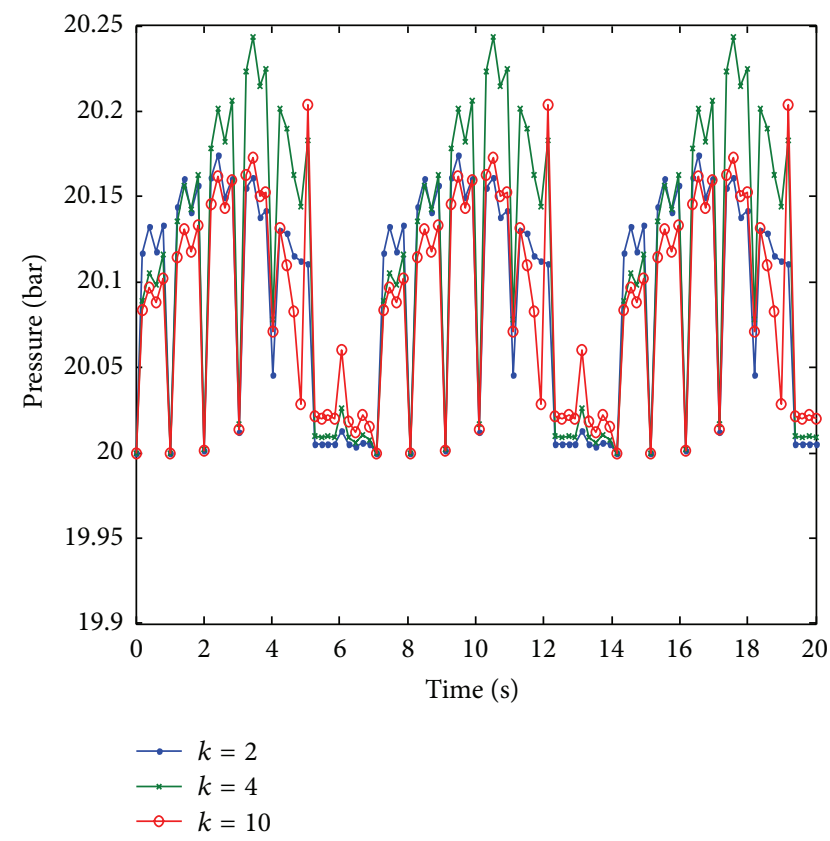

(d) Convex closing valve law $(m=5)$

FIGURE 6: Transient pressure waves and their polygonal approach for different $k$ segments at 33\% of hydrogen-natural gas mixture.

Figure 6 shows the closing valve function and its different polygonal segments. From Figure 6, the patterns of pressure wave of hydrogen-natural gas mixture remain the same for different number of segments at each type of closing law.

Increasing the number of segments $k$ can reduce the pressure wave of hydrogen-natural gas mixture. For concave valve, the minimum pressure wave at $k=10$ is 19.95 bar, compared to $k=2$, where the minimum pressure wave is 20.00 bar. The minimum pressure wave of linear valve is 19.89 bar and 20.00 bar at $k=10$ and $k=2$, respectively.

According to Provenzano et al. [5], the closing valve model gets better as more segments are included in the polygonal approach. Increasing values of polygonal segments also reduces the time to reach a minimum value of the pressure wave. From the results, plotted in Figure 6, the minimum time taken to reach the minimum pressure of hydrogennatural gas mixture is $0.61 \mathrm{~s}$ at $k=10$ (instantaneous closing valve) compared to $1.10 \mathrm{~s}$ at $k=2$ for convex closing valve.

\section{Conclusion}

The relationship between the pressure waves of hydrogennatural gas mixture with the different types of closing valve laws is determined based on the type of closing laws, closure times, and the polygonal segments of the closing function. The different closing laws are analysed based on the different 
mass ratio of hydrogen-natural gas mixture using the reduced order modelling technique. The transient pressure wave increases as the mass ratio of hydrogen is increased for each type of closing law.

The instantaneous closing law $(m=0)$ gives the square form of the pressure wave. For concave closing law $(0 \leq$ $m<1$ ), the pressure wave shape changes from trapezoidal to triangular when $m$ increases. For linear closing law $(m=1)$, the pressure wave is strictly in a triangular form. For convex closing valve $(5<m<50)$, the pressure wave changes from triangular towards trapezoidal shape. Increasing the value of $m$ increases the pressure wave and the time needed for computation. It is found that the instantaneous closing law gives rise to minimum pressure.

The relationship between the pressure waves of hydrogennatural gas mixture (at $33 \%$ of hydrogen content) with various closure times and different number of polygonal segments is also determined. The numerical results show the interaction of the transient pressure wave with the closure time generated by RCV and ACV. Reducing the closure time for both RCV and ACV reduces the transient pressure wave. Closing the valve instantly takes the least time to reduce the pressure wave while the convex closing law takes the longest time to do so.

Increasing the values of polygonal segments denoted by $k$ reduces the pressure wave and time to reach the minimum value. The instantaneous closing law gives lowest pressure while the convex closing law produces the maximum pressure wave when the valve is closing. Thus, to ensure the attainment of minimum pressure within a short time, the instantaneous closing valve must be considered.

It must be noted that to reduce the effects of water hammer phenomenon, devices and procedures such as valve movement, surge tanks, and increased pipeline diameter could be considered to mitigate both high and low pressure and to reduce potential surge pressure $[11,25]$.

\section{Conflict of Interests}

The authors declare that there is no conflict of interests regarding the publication of this paper.

\section{Acknowledgment}

Financial support provided by Vot 00M25 and Vot 01G31, Research University Grant Scheme, Universiti Teknologi Malaysia, is gratefully acknowledged.

\section{References}

[1] H. Afshar, R. Kerachian, M. R. Bazargan-Lari, and A. R. Niktash, "Developing a closing rule curve for valves in pipelines to control the water hammer impacts: application of the NSGAII optimization model," in Proceedings of the 7th International Pipelines Conference (IPC '08), pp. 1-10, American Society of Civil Engineering Pipelines (ASCE), Atlanta, Ga, USA, July 2008.
[2] D. J. Wood, S. Lingireddy, B. W. Karney, and D. L. Mcpherson, "Numerical Methods for modelling transient flow in distribution systems," Journal American Water Works Association, vol. 97, no. 7, pp. 104-115, 2005.

[3] J.-S. Lee, B.-K. Kim, W.-R. Lee, and K.-Y. Oh, "Analysis of water hammer in pipelines by partial fraction expansion of transfer function in frequency domain," Journal of Mechanical Science and Technology, vol. 24, no. 10, pp. 1975-1980, 2010.

[4] B. W. Karney and E. Ruus, "Charts for water hammer in pipelines resulting from valve closure from full opening only," Canadian Journal of Civil Engineering, vol. 12, no. 2, pp. 241-264, 1985.

[5] P. G. Provenzano, F. Baroni, and R. J. Aguerre, "The closing function in the water hammer modeling," Latin American Applied Research, vol. 41, no. 1, pp. 43-47, 2011.

[6] M. S. Ghidaoui, M. Zhao, D. A. McInnis, and D. H. Axworthy, "A review of water hammer theory and practice," Applied Mechanics Reviews, vol. 58, no. 1, pp. 49-76, 2005.

[7] L. F. Menabrea, "Note sur les effets du choc de l'eau dans les conduites," Comptes Rendus Hebdomadaires des Seances de l'Academie des Sciences, vol. 47, pp. 221-224, 1885.

[8] J. Michaud, "Coups de bélier dans les conduites. Étude des moyens employés pour en atténeur les effects," Bulletin de la Société Vaudoise des Ingénieurs et des Architectes, vol. 4, no. 34, pp. 56-64, 65-77, 1878.

[9] B. V. Charles, "Analysis of water hammer in pipes with noncondensable gases," in Proceedings of the AMSE Pressure Vessels and Piping Division Conference (PVP '09), Prague, Czech Republic, 2009.

[10] A. Fouzi and F. Ali, "Comparative study of the phenomenon of propagation of elastic waves in conduits," in Proceedings of the World Congress on Engineering (WCE '11), vol. 3, London, UK, 2011.

[11] B. Mansuri, F. Salmasi, and B. Oghati, "Sensitivity analysis for water hammer problem in pipelines," Iranica Journal of Energy and Environment, vol. 5, no. 2, pp. 124-131, 2014.

[12] S. Elaoud and E. Hadj-Taïeb, "Transient flow in pipelines of high-pressure hydrogen-natural gas mixtures," International Journal of Hydrogen Energy, vol. 33, no. 18, pp. 4824-4832, 2008.

[13] L. Allievi, “Theorie generale du movement varié de l'eau dans les tuyaux de conduit," Mechanical Review, vol. 14, pp. 10-22, 230259, 1904.

[14] V. L. Streeter, "Water hammer analysis," Journal of the Hydraulics Division, vol. 95, no. 6, 1969.

[15] D. C. Wiggert and M. J. Sundquist, "Fixed grid characteristics for pipeline transients," Journal of Hydraulic ASCE, vol. 103, no. 12, pp. 1403-1416, 1977.

[16] C. S. Watt, J. M. Hobbs, and A. P. Boldy, "Hydraulic transients following valve closure," Journal of Hydraulic ASCE, vol. 106, no. 1980, pp. 1627-1640, 1980.

[17] M. H. Chaudhry and M. Y. Hussaini, "Second-order accurate explicit finite-difference schemes for water hammer analysis," Journal of Fluids Engineering, vol. 107, no. 4, pp. 523-529, 1985.

[18] G. Pezzinga, "Evaluation of unsteady flow resistances by quasi2D or 1D models," Journal of Hydraulic Engineering, vol. 126, no. 10, pp. 778-785, 2000.

[19] M. Behbahani-Nejad and Y. Shekari, "The accuracy and efficiency of a reduced-order model for transient flow analysis in gas pipelines," Journal of Petroleum Science and Engineering, vol. 73, no. 1-2, pp. 13-19, 2010. 
[20] M. Behbahani-Nejad and Y. Shekari, "Reduced order modelling of natural gas transient flow in pipelines," International Journal of Engineering and Applied Sciences, vol. 5, no. 7, pp. 148-152, 2008.

[21] M. Behbahani-Nejad, H. Haddadpour, and V. Esfahanian, "Reduced order modelling of unsteady flows without static correction requirement," in Proceedings of the 24th International Congress of the Aeronautical Sciences (ICAS '04), pp. 1-8, Yokohama, Japan, 2004.

[22] B. G. Agaie and N. Amin, "The effect of water hammer on pressure oscillation of hydrogen natural gas transient flow," Applied Mechanics and Materials, vol. 554, pp. 251-255, 2014.

[23] M. Chaczykowski, "Transient flow in natural gas pipelinethe effect of pipeline thermal model," Applied Mathematical Modelling, vol. 34, no. 4, pp. 1051-1067, 2010.

[24] J. Zhou and M. A. Adewumi, "Simulation of transients in natural gas pipelines using hybrid TVD schemes," International Journal for Numerical Methods in Fluids, vol. 32, no. 4, pp. 407437, 2000.

[25] H. Garry, B. Susan, and L. Gregory, "Pipeline surge analysis studies," in Proceedings of the Pipeline Simulation Interest Group Annual Meeting (PSIG '14), Baltimore, Md, USA, 2014. 


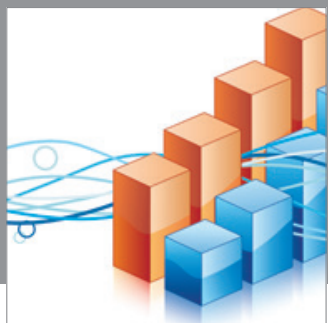

Advances in

Operations Research

mansans

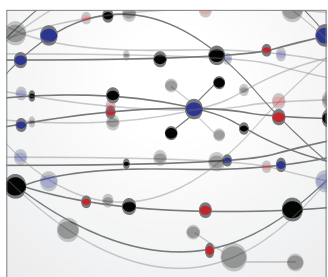

The Scientific World Journal
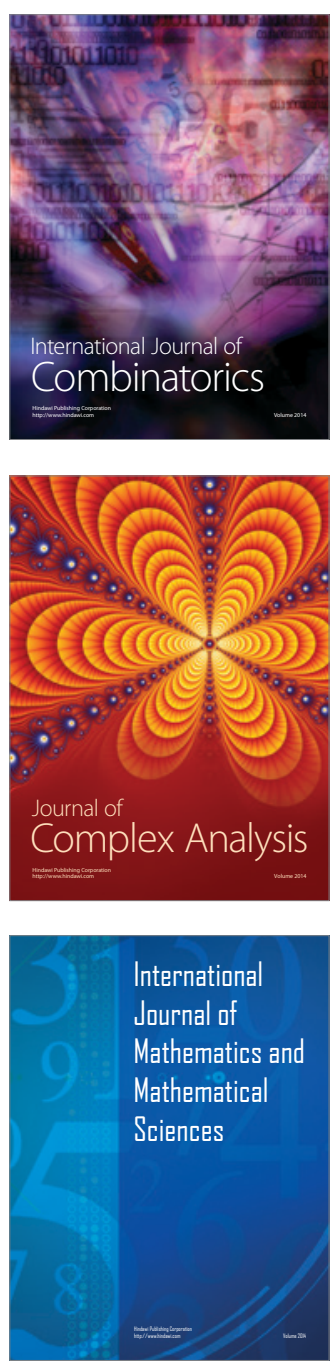
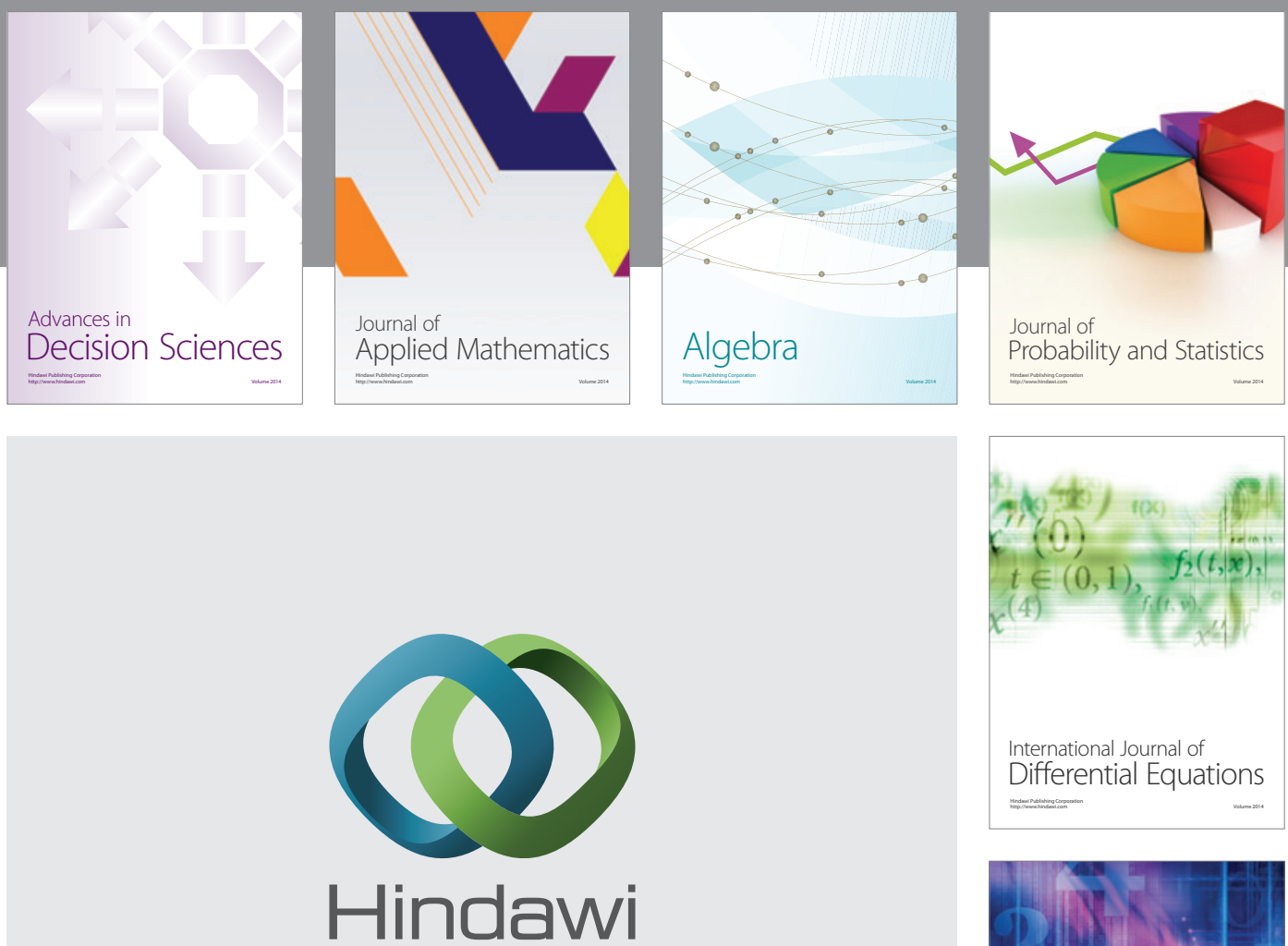

Submit your manuscripts at http://www.hindawi.com
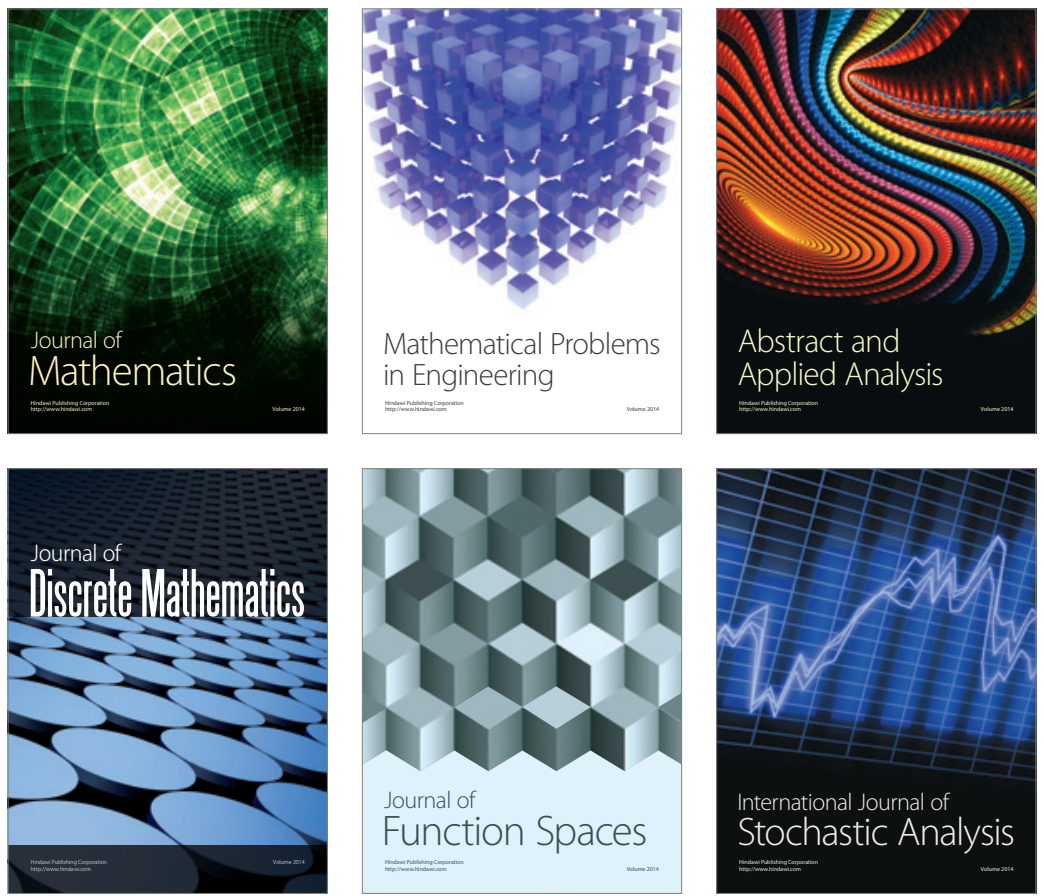

Journal of

Function Spaces

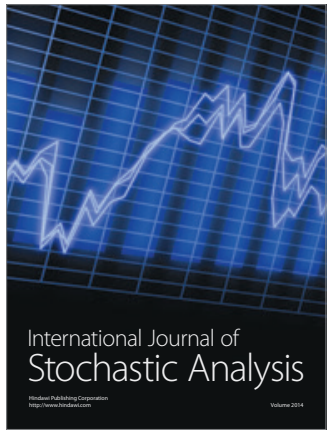

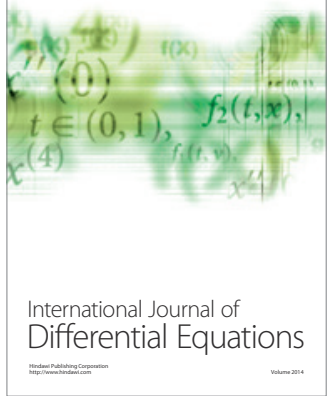
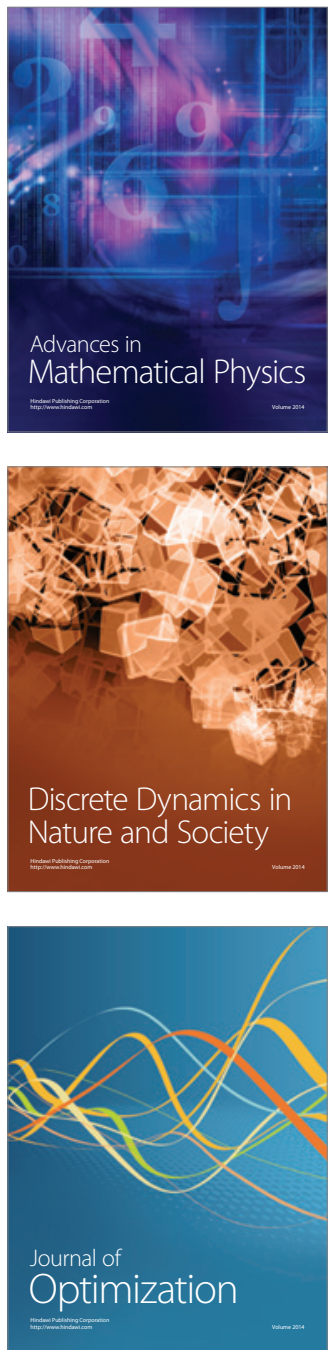